\title{
Gestational Thyrotoxicosis Manifesting as Wernicke Encephalopathy: A Case Report
}

\author{
Fumio OTSUKA, KaTSUHIKo TADA*, Toshio OGURA**, NobuHIKo HAYAKAWA, \\ YUKARI MIMURA, TAKAYOSHI YAMAUCHI, NANAKO INOUE*, \\ HIROFUMI MAKINO, AND TAKAFUMI KUDO* \\ Department of Medicine III and \\ *Department of Gynecology and Obstetrics, Okayama University Medical School, and \\ **Health and Medical Center, Okayama University, Okayama 700, Japan
}

\begin{abstract}
The thyroid gland is physiologically stimulated in normal early pregnancy. This stimulated thyroid function is occasionally termed "gestational transient thyrotoxicosis". The cause of this thyrotoxicosis has been clarified to closely it associate with human chorionic gonadotropin (hCG). We encountered a pregnant patient with hyperemesis and thyrotoxicosis, who manifested symptoms of Wernicke encephalopathy. Although her serum hCG concentration transiently increased in accordance with the thyrotoxicosis, it was within normal limits for the gestational week. Both the thyrotoxicosis and a catabolic state due to the hyperemesis were thought to have induced a vitamin B1 deficiency, causing the Wernicke encephalopathy. This case suggests that pregnant patients with hyperemesis should undergo careful endocrinological and neurological evaluations.
\end{abstract}

Key words: Gestational thyrotoxicosis, Gestational transient hyperthyroidism, Human chorionic gonadotropin (hCG), Wernicke encephalopathy, Hyperemesis gravidarum

(Endocrine Journal 44: 447-452, 1997)

GESTATIONAL thyrotoxicosis refers to the concept of the physiologically active state of the thyroid during normal early pregnancy. Circulating human chorionic gonadotropin (hCG) has been suggested as one etiology of this condition [1-7]. The patient in the present case manifested hyperemesis with thyrotoxicosis, resulting in loss of consciousness attributed to Wernicke encephalopathy. Although subclinical vitamin B1 deficiency can be caused by severe hyperemesis gravidarum, it rarely results in the manifestation

Received: September 9, 1996

Accepted: February 4, 1997

Correspondence to: Dr. Fumio OTSUKA, Department of Medicine III, Okayama University Medical School, 2-5-1 Shikata-cho, Okayama city, Okayama 700, Japan of Wernicke encephalopathy. Our findings emphasize the importance of diagnosing and treating pregnant patients with this complicated emergency accurately and safely. We hope that our presentation of this case will contribute to the clinical recognition of this entity.

\section{Case Report}

A 27-year-old pregnant Japanese woman was transferred to our hospital on Sep. 28, 1995, after experiencing a loss of consciousness. She had been suffering from hyperemesis since July, 1995 and been treated with intravenous hyperalimentation without supplement of vitamins for preceding 2 weeks. Despite this intervention, her pulse rate had gradually increased and her level of 
A

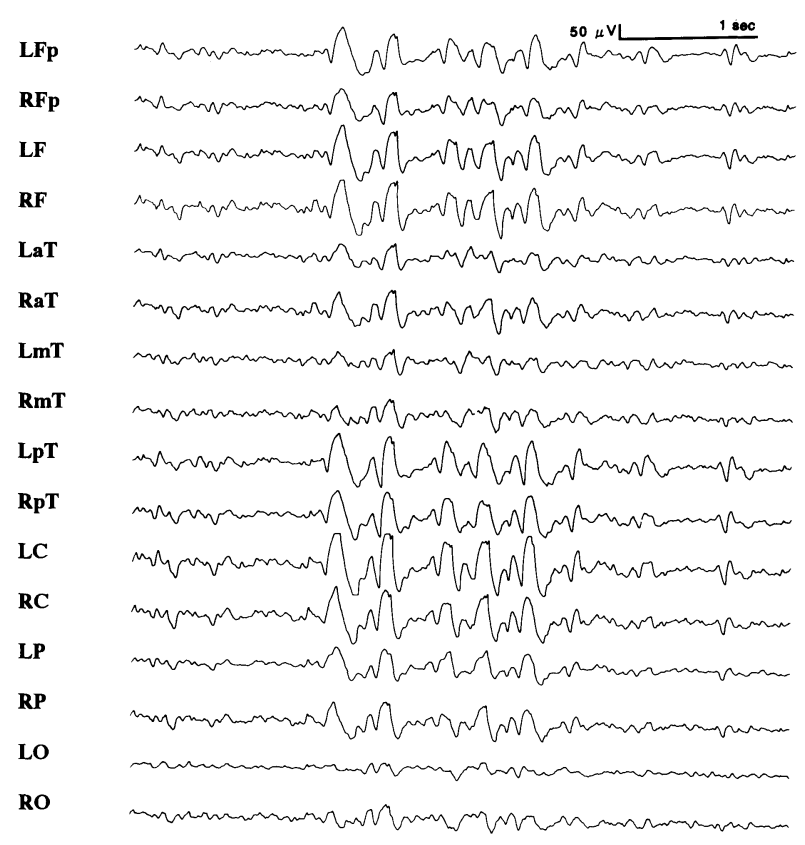

\section{B}

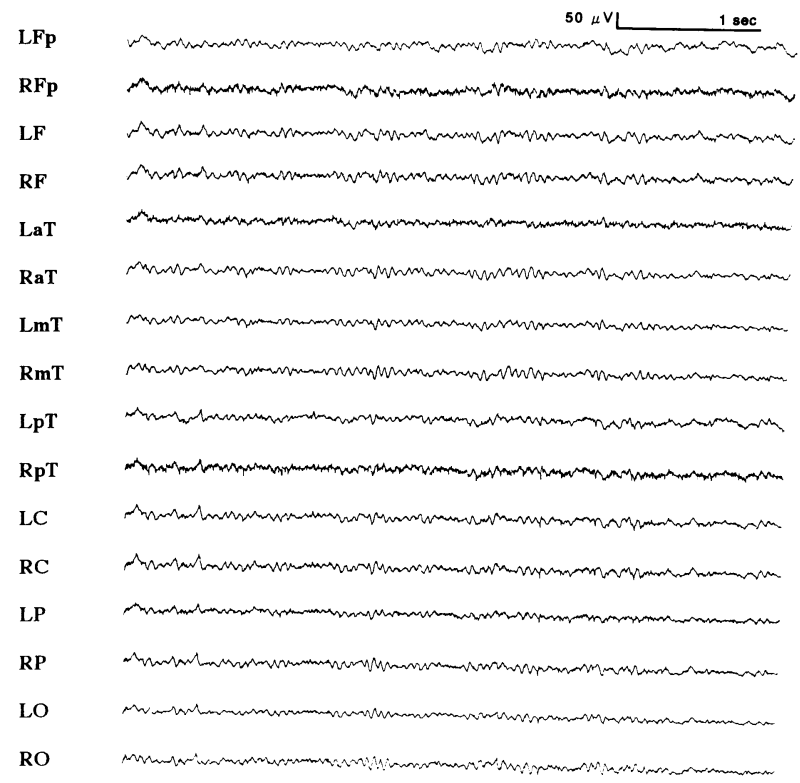

Fig. 1. Electroencephalogram (EEG). Following the loss of consciousness, this patient's EEG showed periodic 3-4 $\mathrm{Hz}$ slow waves over her whole brain (A). Post-treatment, her EEG was completely normal (B).

consciousness had decreased until she experienced convulsions on the day of admission. She had a past history of a spontaneous abortion in 1994, but no past or family history of thyroid disease. She did not drink alcohol or smoke.

Physical examination on admission revealed a comatose state without any response to pain stimulation. Her blood pressure was $111 / 68 \mathrm{~mm}$ $\mathrm{Hg}$ and her pulse was $147 \mathrm{bpm}$ and regular, and body temperature was $37.5^{\circ} \mathrm{C}$. Palpation of the patient's thyroid gland revealed soft diffuse struma without lymphadenopathy. There were no abnormal auscultation findings except for tachycardia. She exhibited mild abdominal distension consistent with a 14-week pregnancy. No pretibial edema was observed. Neurological examination revealed noticeably decreased deep tendon reflexes in all extremities without pathologic reflexes or neck stiffness, and an oculocephalic response was positively observed. On an ophthalmologic examination, she demonstrated a rapid rotatory nystagmus, especially on lateral gaze, and right retinal hemorrhage was also noted. Her pupils were round and isocoric, and both light reflexes were prompt. Although an electro- encephalogram (EEG) showed periodic diffuse slow wave activities involving the whole brain (Fig. 1A), lumbar puncture revealed clear cerebrospinal fluid (CSF) with a normal cell count. CSF sugar and protein concentrations also were normal. Cranial computed tomography exhibited slight swelling of the brain.

She was emergently treated with vitamin B1 (250 $\mathrm{mg} i . v$.) and hydrocortisone (100 $\mathrm{mg}$ i.v.), for a presumptive diagnosis of hyperthyroidism with Wernicke encephalopathy. Hydrocortisone was chosen for rapid alleviation of thyrotoxicosis falling into thyroid crisis. Laboratory examination revealed the following values: red blood cells, 3.35 $\times 106 / \mathrm{mm}^{3}$; hemoglobin, $10.5 \mathrm{~g} / \mathrm{dl}$; white blood

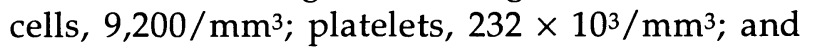
blood glucose, $102 \mathrm{mg} / \mathrm{d} l$. Liver and renal function tests and electrolytes (serum sodium, $142 \mathrm{mmol} / \mathrm{l}$; potassium, $3.8 \mathrm{mmol} / \mathrm{l}$; chloride, $105 \mathrm{mmol} / \mathrm{l}$; calcium, $8.2 \mathrm{mg} / \mathrm{dl}$; inorganic phosphate, $3.4 \mathrm{mg} /$ $\mathrm{d} l$; magnesium, $2.1 \mathrm{mg} / \mathrm{d} l$ ) were within normal limits. Arterial blood gas analysis also was normal. Data obtained from endocrinological examinations are shown in Table 1 . Both serum free triiodothyronine and thyroxine concentration were 
Table 1. Endocrinological data on admission

\begin{tabular}{lrlr}
\hline free triiodothyronine & $8.26 \mathrm{pg} / \mathrm{ml}(4.0-5.8)$ & $\mathrm{ACTH}$ & $33.5 \mathrm{pg} / \mathrm{ml}(4.4-48.0)$ \\
free throxine & $2.77 \mathrm{ng} / \mathrm{d} l(1.03-2.21)$ & $\mathrm{GH}$ & $2.46 \mathrm{ng} / \mathrm{ml}(0.28-8.7)$ \\
thyroid stimulating hormone & $0.02 \mu \mathrm{U} / \mathrm{ml}(0.55-4.8)$ & $\mathrm{LH}$ & $0.12 \mathrm{mIU} / \mathrm{ml}(<0.2)$ \\
thyroglobulin & $150 \mathrm{ng} / \mathrm{ml}(<30)$ & $\mathrm{FSH}$ & $0.04 \mathrm{mIU} / \mathrm{ml}(<1)$ \\
thyroid binding globulin & $23.5 \mu \mathrm{g} / \mathrm{ml}(12-30)$ & $\mathrm{PRL}$ & $174.4 \mathrm{ng} / \mathrm{ml}(14-105)$ \\
antibodies & & & \\
TBII & $7.9 \%(<15)$ & testosterone & $0.4 \mathrm{ng} / \mathrm{ml}(0.1-0.7)$ \\
TSAb & $99 \%(<145)$ & estradiol & $4,000 \mathrm{pg} / \mathrm{ml}(2040-19400)$ \\
TGHA & negative & estriol & $391 \mathrm{pg} / \mathrm{ml}(570-5200)$ \\
MCHA & negative & cortisol & $14.1 \mu \mathrm{g} / \mathrm{d} l(5-21)$ \\
anti-thyroglobulin & negative & aldosterone & $148 \mathrm{pg} / \mathrm{ml}(56.9-150.3)$ \\
anti-thyroid peroxidase & negative & progesterone & $35.2 \mathrm{ng} / \mathrm{m} l(17-146)$ \\
anti-intrinsic factor & negative & human chorionic gonadotropin & $103,000 \mathrm{mIU} / \mathrm{ml}$ \\
anti-parietal cell & negative & arginine vasopressin & $0.5 \mathrm{pg} / \mathrm{ml}(0.8-6.3)$ \\
& & atrial natriuretic peptide & $16.7 \mathrm{pg} / \mathrm{ml}(<43)$ \\
\hline
\end{tabular}

TBII, thyroid binding inhibitory immunoglobulin; TSAb, thyroid stimulating antibody; TGHA, thyroglobulin hemagglutination test; MCHA, microsomal hemagglutination test; values in parenthesis indicate normal values.

increased, and TSH was suppressed. Serum thyroglobulin was also increased. Thyroidal autoantibodies were not detected. Her serum hCG concentration was increased $(103,000 \mathrm{mIU} / \mathrm{ml})$ to a level compatible with a 14-week pregnancy. Her serum PRL concentration also was mildly increased, and estriol was slightly decreased. These endocrinological data suggested thyrotoxicosis little involving an autoimmune mechanism. Although no specimens for determination of serum vitamin content before treatment were available, her serum vitamin B1 level was increased to $100 \mathrm{ng} / \mathrm{ml}$ (normal: $20-50 \mathrm{ng} / \mathrm{ml}$ ) following the administration of vitamins, and her pyruvate level was increased to $1.03 \mathrm{mg} / \mathrm{d} l$ (normal: $0.3-0.9 \mathrm{mg} / \mathrm{d} l$ ). Transketolase in red blood cells was $0.86 \mathrm{IU} / \mathrm{g}$ $\mathrm{Hb}$, representing the lower level of normal (normal: $0.75-1.3 \mathrm{IU} / \mathrm{g}-\mathrm{Hb}$ ). On cervical echography, the thyroid gland appeared diffusely swollen with entirely homogeneous highly echogenicity (Fig. 2A). Three days after the administration of hydrocortisone and vitamins, her level of consciousness rapidly improved to almost alert and her speech was smooth but sometimes contained confused accounts manifesting Korsakoff symptom. The administration of thiamazole ( $30 \mathrm{mg}$ p.o.) and propranolol (20 mg p.o.) was then initiated, and her serum thyroid hormones and pulse rate normalized in accordance with a decrease in hCG. Although her tendon reflexes showed complete recovery 3 weeks after the admission, her ataxic gait has been remarkable as starting a rehabilitation. Her pyruvate level gradually decreased, while the

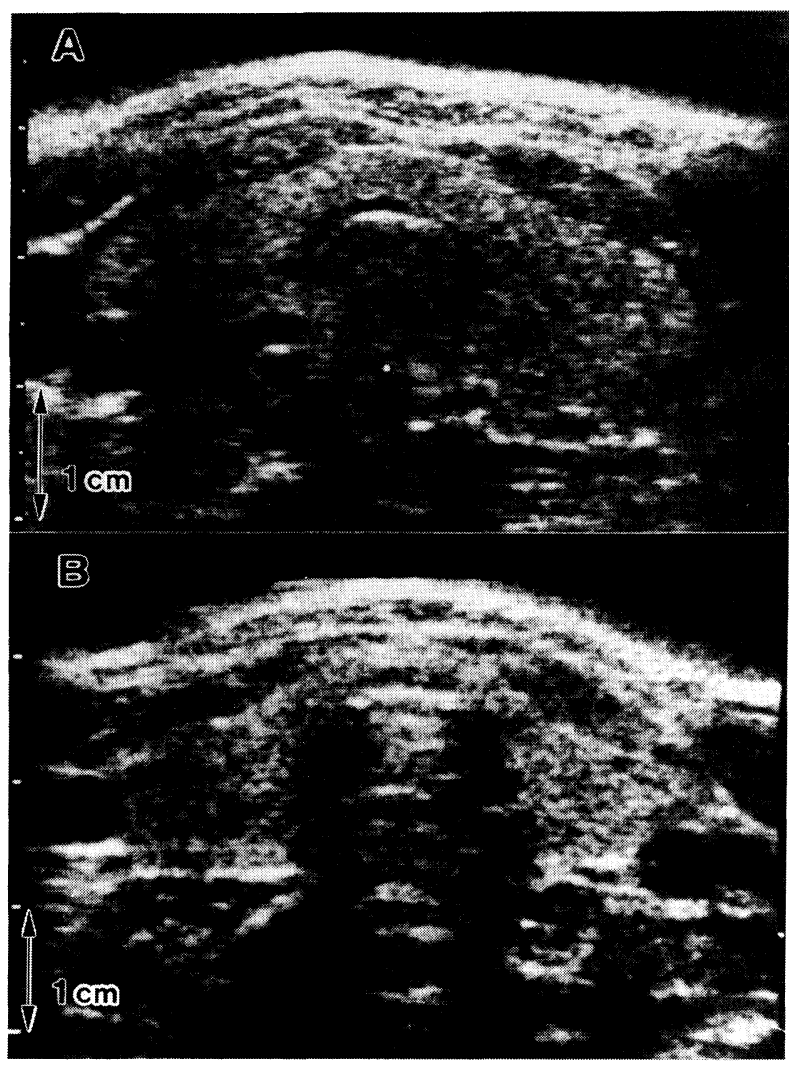

Fig. 2. Echogram of the thyroid gland. On admission, thyroid echography showed diffuse swelling with an entirely homogeneous high echogenicity. The sizes were as follows: left lobe, $4.7 \times 2.8 \times 1.8 \mathrm{~cm}$; right lobe, $4.8 \times 3.0 \times 1.9 \mathrm{~cm}$; thickness of isthmus, $0.5 \mathrm{~cm}$ (A). After normalization of her thyroid function, echographic findings showed a diminished thyroid gland size. The sizes were as follows: left lobe, $4.3 \times 2.4 \times 1.6 \mathrm{~cm}$; right lobe, $4.3 \times$ $2.5 \times 1.7 \mathrm{~cm}$; thickness of isthmus, $0.25 \mathrm{~cm}$ (B). 


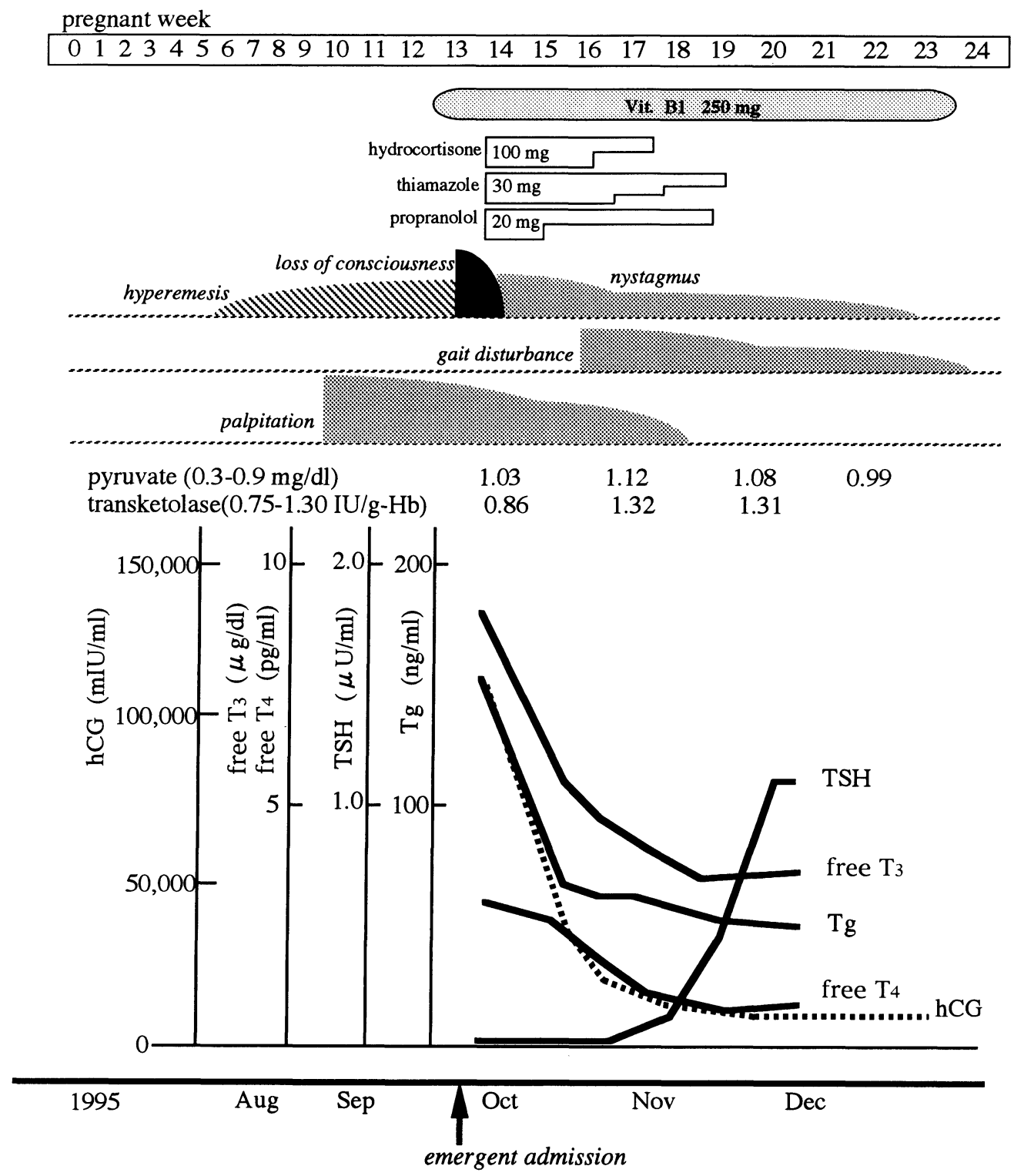

Fig. 3. The clinical course. The patient's level of consciousness was severely decreased on admission. After treatment with vitamin B1 and hydrocortisone, her level of consciousness rapidly improved. Thiamazole and propranolol were administered to treat the thyrotoxicosis. As the level of human chorionic gonadotropin (hCG) decreased, the thyrotoxicosis gradually improved. The symptoms of Wernicke encephalopathy resolved in parallel with her endocrinological recovery.

transketolase level in her red blood cells remained high. Both the nystagmus and gait disturbance continued for approximately 2 months before gradually improving (Fig. 3). In Nov. 1995, a repeat EEG was normal (Fig. 1B) and then the right retinal hemorrhage completely disappeared on ophthalmologic examination, and in Dec. 1995, a repeat thyroid echogram revealed diminished size of the previous thyroidal enlargement (Fig. 2B). She continued a normal pregnant course, and gave birth to a girl weighing 2,066 $\mathrm{g}$ (light for date) on Apr. 4th, 1996 (41-week pregnancy) with normal delivery. The baby has been growing normaly both endocrinologically and neurologically, and the 
patient's symptoms have improved adequately. No postpartum thyroidal dysfunction has been observed, and a postpartum sequential thyroidal echogram result was almost the same compared as in Fig. 2B.

\section{Discussion}

Thyroid dysfunction in early pregnancy has been studied, and termed "gestational thyrotoxicosis" or "gestational transient hyperthyroidism" [1, 2]. Gestational thyrotoxicosis has been reported to be associated not only with increased circulating hCG, but also with hyperemesis gravidarum $[1,3,5,7$, 8]. Glycoproteins such as hCG, LH, FSH and TSH contain a common $\alpha$-subunit, and the structures of the $\beta$-subunit in TSH and hCG resemble one another. It has been suggested that large amounts of hCG bind TSH receptors and stimulate thyroid cells [3]. In trophoblastic disorders, abnormal hCG production manifests as hyperthyroidism [9], and even in normal subjects, high serum hCG in early pregnancy can stimulate the thyroid gland, sometimes causing overt hyperthyroidism [4]. Although the pathogenesis of gestational hyperthyroidism has not been clarified completely, an association with the asialo-hCG or $\beta$-subunit of hCG has recently been reported $[2,6]$. It therefore appears that hCG probably does stimulate the thyroid gland in pregnancy, causing increased thyroid hormone levels, resulting in gestational thyrotoxicosis. The failure to confirm this hypothesis in some studies [10] perhaps indicates that further clarification of the structure of hCG, and other putative thyroid stimulators in normal pregnancy, is required. In this case, we could not determine what stimulation of the thyroid gland resulted in the differences between thyroidal echograms obtained pre- and post-therapy. Nevertheless, because thyroid hormone decreased in accordance with the decrease in hCG, hCG is thought to have been a potent thyroidal stimulating factor.

The relationship between Wernicke encephalopathy and thyrotoxicosis was first reported in 1968 [11], and has been explained by the decreased intake, increased utilization and malabsorption of thiamin. The case of the present patient was complicated by hyperemesis gravidarum, thyrotoxicosis and Wernicke encephalopathy. The former two factors probably were caused by circulating hCG inducing a severely catabolic state. Moreover, decreased intake and malabsorption may have induced vitamin B1 deficiency. In fact, the intravenous administration of thiamin was so effective that the patient became alert a few days after the treatment. This patient gave birth to a girl weighing light for date, suggesting that long-term malnutrition in the mother may strongly affect the growth of the embryo and fetus, but the continuable pregnancy and the normal growth of the child were probably attributable to the fact that this patient's severe state was fortunately located outside of the organogenic phase of the embryo (Fig. 3). Although Wernicke encephalopathy is now quite rare, we should take into consideration that this disease, manifesting as the triad of a decreased level of consciousness, ocular symptoms and a gait disturbance, may still occur in susceptible individuals (pregnant patients, alcoholics, patients with malnutrition and/or thyrotoxicosis). To diagnose Wernicke encephalopathy, the determination of blood vitamin B1 and/or transketolase levels, with or without thiamindisphosphate (the TPP effect) is occasionally required, but in an emergency, sufficient thiamin should always be administered while awaiting the results of laboratory tests, since postponed therapy can lead to a poor prognosis. In general, gestational transient thyrotoxicosis tends to increase thyroxine rather than triiodothyronine [1-3]. Since the thyrotoxicosis in this case involved an increase predominantly in triiodothyronine rather than thyroxine, steroid therapy for suppression of the peripheral conversion of thyroxine was probably effective as a therapeutic option, but we must be aware of the transplacental effects of drugs when treating pregnant patients.

The clinical features of this pregnant patient suffering thyroidal dysfunction were probably due to the combination of a normal transient increase in hCG, vitamin B1 deficiency secondary to hyperemesis gravidarum, and thyrotoxcosis. This case suggests that, even in a normal pregnancy, we should take into consideration that endocrinological dysfunction can be caused by various placental factors. 


\section{References}

1. Kimura M, Amino N, Tamaki H, Ito E, Mitsuda N, Miyai K, Tanizawa O (1993) Gestational thyrotoxicosis and hyperemesis gravidarum: Possible role of hCG with higher stimulating activity. Clin Endocrinol 38: 345-350.

2. Tsuruta E, Tada H, Tamaki H, Kahiwai T, Asahi K, Takeoka K, Mitsuda N, Amino N (1995) Pathologic role of asialo human chorionic gonadotropin in gestational thyrotoxicosis. J Clin Endocrinol Metab 80: 350-355.

3. Kennedy RL, Darne J, Davis R, Price A (1992) Thyrotoxicosis and hyperemesis gravidarum associated with a serum activity which stimulates human thyroid cells in vitro. Clin Endocrinol 36: 8389.

4. Kimura M, Amino N, Tamaki H, Mitsuda N, Miyai K, Tanizawa O (1990) Physiologic thyroid activation in normal early pregnancy is induced by circulating hCG. Obstet Gynecol 75: 775-778.

5. Goodwin TM, Montro M, Mestman JH, Pekary AE, Hershman JM (1992) The role of chorionic gonadptropin in transient hyperthyroidism of hyperemesis gravidarum. J Clin Endocrinol Metab 75: $1333-1337$
6. Glinoer D, Nayer PD, Robyn C, Lejeune B, Kinthaert J, Meuris S (1993) Serum levels of intact human chorionic gonadotropin (HCG) and its free $\alpha$ and $\beta$ subunits, in relation to material thyroid stimulation during normal pregnancy. J Endocrinol Invest 16: 881-888.

7. Lazarus JH (1993) Pregnancy, hCG, thyrotoxicosis and hyperemesis gravidarum. Clin Endocrinol 38: 343.

8. Mori M, Amino N, Tamaki H, Miyai K, Tanizawa O (1988) Morning sickness and thyroid function in normal pregnancy. Obstet Gynecol 72: 355-359.

9. Cain HJ, Pannall PR, Kotasek D, Norman RJ (1981) Choriogonadotropin-mediated thyrotoxicosis in a man. Clin Chem 37/6: 1127-1131.

10. Wilson R, McKillop JH, McLean M, Walker JJ, Fraser WD, Gray C, Dryburgh F, Thomson JA (1992) Thyroid function tests are rarely abnormal in patients with severe hyperemesis gravidarum. Clin Endocrinol 37: 331-334.

11. Enoch BA, Williams DM (1968) An association between Wernicke's encephalopathy and thyrotoxicosis. Postgrad Med J 44: 923-930. 